\title{
Use of dihydropyridine calcium channel blockers in the management of hypertension in Eastern Asians: A scientific statement from the Asian Pacific Heart Association
}

\author{
Ji-Guang Wang ${ }^{1}$, Kazuomi Kario ${ }^{2}$, Titus Lau ${ }^{3}$, Yong Quek Wei ${ }^{4}$, Chang Gyu Park ${ }^{5}$, Cheol Ho Kim ${ }^{6}$, \\ Jun Huang ${ }^{7}$, Weizhong Zhang ${ }^{1}$, Yong $\mathrm{Li}^{8}$, Peter Yan ${ }^{9}$ and Dayi $\mathrm{Hu}^{10}$
}

Dihydropyridine calcium channel blockers (CCBs) are widely prescribed for the management of hypertension in Eastern Asians. In this study, the Asian Pacific Heart Association's Writing Committee reviewed randomized controlled trials that were conducted in the Eastern Asian region and compared a CCB with an antihypertensive drug of another class. These trials studied ambulatory blood pressure, measures of target organ damage and cardiovascular events as outcomes. Eleven trials studied ambulatory blood pressure in hypertensive patients and demonstrated that the 24-h blood pressure reduction with CCBs was greater than with other classes of antihypertensive drugs, with a weighted mean difference of $5 \mathrm{~mm} \mathrm{Hg}$ systolic and $3 \mathrm{~mm} \mathrm{Hg}$ diastolic. Twelve trials that studied various measurements of target organ damage in hypertensive patients produced inconsistent results when comparing CCBs and other classes of antihypertensive drugs. Four trials that studied the hard outcomes had limited power, but confirmed the findings of previous placebo-controlled trials in the region and actively controlled trials in Europe and North America; they suggested that CCBs provided superior protection against stroke and that some agents, such as amlodipine, also provided similar protection against myocardial infarction. In conclusion, CCBs should be recommended as a preferred drug for the management of hypertension in the Eastern Asian region to improve blood pressure control and to confront the aggravating epidemic of stroke and coronary heart disease.

Hypertension Research (2011) 34, 423-430; doi:10.1038/hr.2010.259; published online 13 January 2011

Keywords: ambulatory blood pressure; calcium channel blockers; cardiovascular endpoints; randomized controlled trials; target organ damage

\section{INTRODUCTION}

In the Eastern Asian region, dihydropyridine calcium channel blockers (CCBs) are the most widely prescribed drug class for the management of hypertension. According to the 2008 Intercontinental Marketing Services report, $\sim 40 \%$ of treated hypertensive patients in this region took a dihydropyridine CCB. The orally administered agents available on the market and their major pharmacokinetic properties are shown in Table 1. CCBs are also the drug class in the Eastern Asian region with the most evidence-based research supporting their efficacy. Several placebo-controlled antihypertensive trials in China have employed a dihydropyridine $\mathrm{CCB}$ as the first-line drug for hypertension treatment. ${ }^{1-5}$ Indeed, nitrendipine was used in the Syst-China
(Systolic Hypertension in China trial), ${ }^{1,2}$ nifedipine in the Shanghai trial $^{3}$ and felodipine in the FEVER (Felodipine Event Reduction) trial. ${ }^{4}$ Despite the fact that these CCBs are short or intermediate acting, active antihypertensive treatment significantly reduced the risk of fatal and non-fatal strokes, the major complication of hypertension in the Chinese population, by 38,58 and $27 \%$ in the Syst-China, ${ }^{1}$ Shanghai ${ }^{3}$ and FEVER trials, ${ }^{4}$ respectively.

In addition to the evidence from these trials, several other factors might also contribute to the use of dihydropyridine CCBs in Eastern Asians. First, CCBs are probably more effective in lowering blood pressure in Eastern Asians, because, when compared with the White population, Eastern Asians have high dietary intakes of sodium ${ }^{5}$ and

\footnotetext{
${ }^{1}$ Centre for Epidemiological Studies and Clinical Trials, Ruijin Hospital, The Shanghai Institute of Hypertension, Shanghai Jiaotong University School of Medicine, Shanghai, China; ${ }^{2}$ Department of Cardiovascular Medicine, Jichi Medical University School of Medicine, Tochigi, Japan; ${ }^{3}$ Department of Medicine, National University Hospital, Singapore; ${ }^{4}$ Department of Cardiology, Tan Tock Seng Hospital, Singapore; ${ }^{5}$ Division of Cardiology, Department of Internal Medicine, Guro Hospital, Korea University School of Medicine, Seoul, Korea; ${ }^{6}$ Department of Internal Medicine, Bundang Hospital, Seoul National University College of Medicine, Sungnam, Korea; ${ }^{7}$ Department of Cardiology, The First Affiliated Hospital, Nanjing Medical University, Nanjing, China; ${ }^{8}$ Department of Cardiology, Hushan Hospital, Shanghai Medical College, Fudan University, Shanghai, China; ${ }^{9}$ Gleneagles Hospital and Mount Elizabeth Hospital, Singapore and ${ }^{10}$ Department of Cardiology, Renmin Hospital, Beijing University, Beijing, China

Correspondence: Professor J-G Wang, The Shanghai Institute of Hypertension, Ruijin 2nd Road 197, Shanghai 200025, China.

E-mail: jiguangw@gmail.com

Asian Pacific Heart Association Writing Committee on the Use of Calcium Channel Blockers in the Management of Hypertension in Eastern Asians.

Received 2 September 2010; revised 12 October 2010; accepted 13 October 2010; published online 13 January 2011
} 
Table 1 Major pharmacokinetic properties of the orally administered dihydropyridine calcium channel blockers

\begin{tabular}{|c|c|c|c|}
\hline Calcium channel blocker & $\begin{array}{c}\mathrm{t}_{\max } \\
(h)\end{array}$ & $\begin{array}{c}\text { Half-life } \\
\text { (h) }\end{array}$ & $\begin{array}{c}V d \\
(\mathrm{l} / \mathrm{kg})\end{array}$ \\
\hline Amlodipine & $6-12$ & $35-50$ & 21 \\
\hline Azelnidipine & 3 & 16 & NR \\
\hline Barnidipine & $1-6$ & 10 & NR \\
\hline Benidipine & $0.8-1.1$ & 2 & NR \\
\hline Cilnidipine & $1.8-2.2$ & 2.5 & NR \\
\hline Efonidipine & 3.6 & 2 & NR \\
\hline Felodipine (extended release) & $2.5-5$ & $11-16$ & 10 \\
\hline Isradipine & 1.5 & $8-12$ & 4 \\
\hline Lacidipine & 5 & $12-15$ & NR \\
\hline Lercanidipine & $1.5-3$ & $8-10$ & NR \\
\hline Manidipine & $1-2$ & 5 & NR \\
\hline Nicardipine & $0.5-2$ & $1-4$ & NR \\
\hline Nifedipine & 0.5 & 2 & $0.6-1.4$ \\
\hline Nifedipine (retard, coat-core or controlled release) & $1.6-4$ & 7 & NR \\
\hline Nitrendipine & 1.5 & 8 & 13.4 \\
\hline Nisoldipine (extended release) & 1 & $7-12$ & $2.7-5.9$ \\
\hline Nilvadipine & $1-2$ & $15-20$ & NR \\
\hline
\end{tabular}

Abbreviations: NR, not reported; $t_{\max }$, time to maximal plasma concentration; Vd, volume distribution.

are more likely to be salt sensitive. ${ }^{6}$ Second, CCBs, compared with other classes of antihypertensive drugs, provide more protection against stroke, ${ }^{7,8}$ hence, they are more relevant because the major complication of hypertension in Eastern Asians is stroke rather than myocardial infarction. In the recent Chinese FEVER trial, the incidence of stroke and coronary events was 15.9 and 6.2 per 1000 patientyears, respectively. ${ }^{4}$ Third, dihydropyridine CCBs are particularly useful in the prevention and amelioration of coronary spasm, which is more prevalent in Japanese patients than in Europeans. ${ }^{9,10}$ Indeed, the incidence of coronary spasm after acetylcholine injection was 47 and $15 \%$ of arteries, respectively, in 15 Japanese and 19 European patients within 14 days of an acute myocardial infarction $(P<0.0001){ }^{9}$

The Asian Pacific Heart Association's Writing Committee studied the efficacy of dihydropyridine CCBs in lowering blood pressure and in preventing target organ damage and cardiovascular events. We searched the Chinese, English, Japanese and Korean literature for relevant studies. The electronic search was based on a combination of the keywords 'calcium channel blocker', 'randomized controlled trial' and at least one of the following: 'ambulatory blood pressure,' 'left ventricular mass,' 'intravascular ultrasound,' 'quantitative coronary angiography,' 'computed tomography angiography,' 'cerebral blood flow, 'albuminuria,' 'proteinuria,' 'intima-media thickness (IMT),' 'pulse wave velocity (PWV),' 'flow-mediated dilation,' 'microcirculation,' 'stroke' or 'myocardial infarction.' For inclusion in this document, trials must have been conducted in an Eastern Asian country, have a randomized controlled design, have compared a CCB with an antihypertensive drug of another class, and studied the 24-h ambulatory blood pressure and measures of target organ damage or cardiovascular events as outcomes.

\section{EFFICACY IN LOWERING AMBULATORY BLOOD PRESSURE}

Numerous studies have been conducted in Eastern Asian countries to compare various antihypertensive regimens. These studies were typically sponsored by the pharmaceutical industry, often had an open design, and were thus vulnerable to observer bias. We therefore restricted our review to trials that assessed blood pressure by ambulatory blood pressure monitoring. In contrast to mercury sphygmomanometry, this method is less influenced by observer bias and the white coat effect, and provides a large number of blood pressure readings measured during the day and night. In addition, the efficacy of a blood pressure-lowering regimen is dependent not only on the choice of drug or drug class but also on the dosage and combination with other antihypertensive drugs. Thus, the trials included in this part of the review compared monotherapies with a long-acting dihydropyridine $\mathrm{CCB}$ and a long-acting antihypertensive drug of another class.

We identified 11 eligible trials, including 6 trials conducted in China ${ }^{11-16}$ and 5 in Japan, ${ }^{17-21} 2$ had a cross-over design ${ }^{17,20}$ and 9 had a parallel group design. ${ }^{11-16,18,19,21}$ Characteristics of these trials are shown in Table 2. Briefly, 10 trials had an open design and 1 was a double-blind trial. The sample size ranged between 15 and 100. All randomized patients had hypertension, although the definition of hypertension varied. The CCB was amlodipine in 10 trials and nifedipine gastrointestinal therapeutic system (GITS) in 1 trial. These 11 trials included 12 control groups, of which 6, 4, 1 and 1 used angiotensin-converting enzyme (ACE) inhibitors, angiotensin receptor blockers (ARB), a diuretic and a $\beta$-blocker, respectively. These study drugs were initiated at the low dose and titrated to the high dose(s) to achieve the goal blood pressure, usually below 140/ $90 \mathrm{~mm} \mathrm{Hg}$. Two trials ${ }^{19,21}$ included a small fraction of patients with additional non-study antihypertensive drugs $(<20 \%$ in both trials). Nonetheless, these two trials were also included.

The mean or median follow-up time was $<6$ months in 9 of the 11 trials. These trials showed the superiority of CCBs over the control groups in controlling ambulatory blood pressure, with a difference in 24-h ambulatory systolic blood pressure ranging from $2 \mathrm{~mm} \mathrm{Hg}$ (see ref. 11) to $11 \mathrm{~mm} \mathrm{Hg}$ (see ref. 12) (Table 2). Overall, the weighted mean differences in the 24-h systolic/diastolic blood pressure between CCBs and control drugs were $5 / 3 \mathrm{~mm} \mathrm{Hg}$. The difference seemed to occur over the whole day, but was more pronounced with nighttime blood pressure measurements. The difference in nighttime systolic blood pressure ranged from $2 \mathrm{~mm} \mathrm{Hg}$ (see ref. 11) to $15 \mathrm{~mm} \mathrm{Hg}$ (see ref. 12). The weighted mean differences in nighttime systolic/diastolic blood pressure were $7 / 4 \mathrm{~mm} \mathrm{Hg}$.

These results were consistent across studies of cross-over $v$ s. parallel group designs, across studies in China and Japan, and across studies of amlodipine or other CCBs as the tested drug and studies of ACE inhibitors or other classes of drugs as the control drug. However, the blood pressure difference was greater in the only blinded trial ${ }^{12}$ than in the 10 trials with open designs.

Only 1 trial was truly conducted in a double-blind manner. ${ }^{12}$ In this double-blind, double-dummy trial, after a 4 -week placebo run-in period, eligible patients (18-80 years of age) with an elevated diastolic blood pressure $(95-115 \mathrm{~mm} \mathrm{Hg})$ or isolated systolic hypertension (systolic blood pressure $>160 \mathrm{~mm} \mathrm{Hg}$ and diastolic blood pressure $<95 \mathrm{~mm} \mathrm{Hg}$ ) were randomly assigned to receive once-daily treatment with amlodipine $(5 \mathrm{mg})$ or enalapril $(5 \mathrm{mg})$ for 14 weeks. Treatment doses were titrated at weeks 4 and 8 , if necessary, according to blood pressure response and the patient's ability to tolerate the dose. Patients underwent 24-h ambulatory blood pressure monitoring at the end of the placebo run-in, after the first and last doses of active treatment, and $48 \mathrm{~h}$ after the discontinuation of treatment to determine the duration of drug action and to mimic the effect of two missed doses. Thirty-seven patients in each group completed the active treatment phase. After 14 weeks of treatment, amlodipine (mean (s.d.) final dose, $6.3(2.3) \mathrm{mg}$ ) produced greater systolic/diastolic blood pressure 


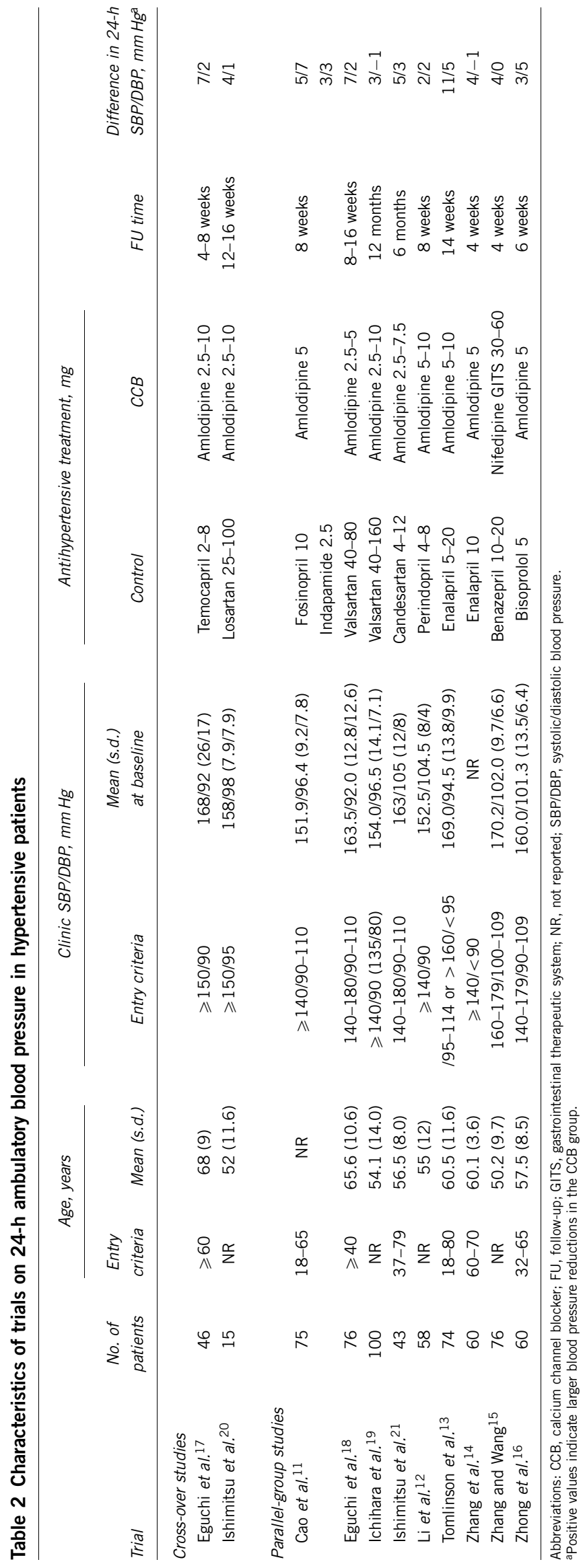

reductions than enalapril (mean (s.d.) final dose, 13.3 (6.6) $\mathrm{mg}$ ) over $24 \mathrm{~h}(-19.5 /-10.4$ vs. $-8.2 /-5.4 \mathrm{~mm} \mathrm{Hg} ; P \leqslant 0.02)$, in the daytime $(-19.5 /-10.0$ vs. $-9.9 /-6.1 \mathrm{~mm} \mathrm{Hg} ; P<0.01)$ and at night $(-20.3 /$ -11.7 vs. $-5.6 /-3.9 \mathrm{~mm} \mathrm{Hg} ; P<0.01)$. Most of the effect of amlodipine persisted for $72 \mathrm{~h}$ after the last dose $(24 \mathrm{~h},-14.4 /-8.2 \mathrm{~mm} \mathrm{Hg}$; daytime, -13.8/-8.0 mm Hg; nighttime, $-13.6 /-7.7 \mathrm{~mm} \mathrm{Hg}$ ), but enalapril had no significant antihypertensive effect at $72 \mathrm{~h}(24 \mathrm{~h},-3.3 /-1.8 \mathrm{~mm} \mathrm{Hg}$; daytime, $-4.3 /-2.3 \mathrm{~mm} \mathrm{Hg}$; nighttime, $-1.9 /-1.1 \mathrm{~mm} \mathrm{Hg}$ ).

The results of these trials suggest that Eastern Asians might have a better blood pressure response to CCBs than to other classes of antihypertensive drugs. However, their long duration of action might also have an important part in the more prominent blood pressure reductions by CCBs, particularly amlodipine.

Next, we performed a meta-regression analysis to investigate to what extent the mean blood pressure reduction in each trial was dependent on the mean baseline blood pressure in the CCB and control groups separately. In the CCB groups, both daytime and nighttime systolic blood pressure reduction was significantly $(P \leqslant 0.05)$ and positively associated with blood pressure at baseline, with an enhanced reduction in blood pressure in the trials with a higher mean baseline blood pressure (Figure 1). However, in the control groups, the association was weak and not statistically significant $(P \geqslant 0.23)$ across a large range of blood pressures.

\section{PROTECTION AGAINST TARGET ORGAN DAMAGE}

This part of our review focused on randomized controlled trials that investigated the effects of CCBs $v s$. other classes of antihypertensive drugs on various measures of target organ damage, such as left ventricular hypertrophy, carotid IMT, carotid femoral or brachial-ankle PWV and albuminuria, as proposed by the Chinese ${ }^{22}$ and Japanese ${ }^{23}$ guidelines on the management of hypertension. Trials in patients with congestive heart failure or end-stage renal disease were excluded.

We identified 12 eligible trials, including 9 trials conducted in Japan ${ }^{19,21,24-30}$ and 3 in China. ${ }^{15,16,31}$ The characteristics of these trials are shown in Table 3. Briefly, all trials had an open design. The sample size ranged between 22 and 183. The study subjects had hypertension in all 12 trials; in several trials, study participants had co-morbid conditions such as type 2 diabetes mellitus, ${ }^{24,26}$ coronary artery disease $^{27}$ and renal impairment. ${ }^{25}$ Twelve trials included 14 CCB groups and 13 control groups. The CCB was amlodipine in 6 trials, nifedipine GITS, retard, coat-core or controlled release in 5 trials, cilnidipine in 2 trials and efonidipine in 1 trial. The control drug was an ACE inhibitor in 6 trials, an ARB in 6 trials and a $\beta$ blocker in 1 trial. These study drugs were initiated with the standard dose; in 7 trials $15,19,21,24,25,27,31$ they were titrated to the high dose(s), and in 3 trials $^{19,21,27}$ they were also combined with additional non-study antihypertensive drugs to achieve the goal blood pressure, usually below 140/90 $\mathrm{mm} \mathrm{Hg}$ of the conventional blood pressure.

Four trials studied brachial-ankle PWV using four different CCBs (amlodipine, ${ }^{19,26}$ nifedipine controlled release ${ }^{26,30}$ or coat-core ${ }^{28}$ or cilnidipine $\mathrm{e}^{30}$ ) in comparison with an ACE inhibitor (temocapril) ${ }^{30}$ or ARBs (candesartan ${ }^{26}$ or valsartan ${ }^{19,28,30}$ ). Amlodipine was compared with valsartan in 100 untreated hypertensive patients (50 subjects per group $)^{19}$ and with candesartan in 16 hypertensive, diabetic patients (11 vs. 5 subjects). ${ }^{26}$ In untreated hypertensive patients, after 12 months of follow-up, amlodipine and valsartan decreased brachialankle PWV similarly. Furthermore, amlodipine yielded a slightly and non-significantly greater reduction in the 24 -h systolic blood pressure $(3 \mathrm{~mm} \mathrm{Hg})$ and significantly greater reductions in the variability of 24-h and daytime ambulatory systolic blood pressure. ${ }^{19}$ However, in a small trial of diabetic and hypertensive patients, after 3 months of 


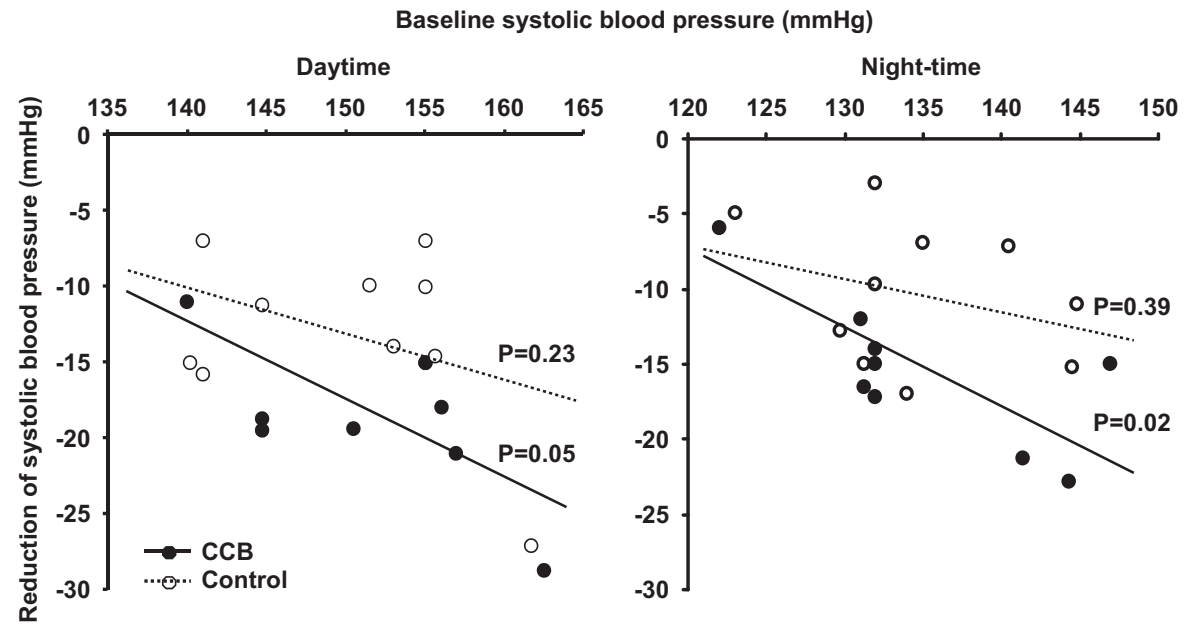

Figure 1 Relation between the mean reduction and baseline level of daytime and nighttime systolic blood pressure by randomization group. The analysis included 10 calcium channel blocker (CCB) groups and 9 control groups from 9 trials, ${ }^{11-19}$ respectively. Two trials were excluded, because daytime and nighttime blood pressures were not reported. ${ }^{20,21}$ The regression line was plotted for the CCB (dot) and control (circle) groups separately, and weighted by the sample size of trials.

follow-up, amlodipine reduced brachial-ankle PWV significantly less than candesartan $\left(157\right.$ vs. $\left.637 \mathrm{~cm} \mathrm{~s}^{-1} ; P<0.01\right) .{ }^{26}$ Nifedipine controlled release $\mathrm{e}^{26,30}$ or coat-core ${ }^{28}$ was compared with valsartan in 41 middle-aged (mean age 54 years; 20 vs. 21 subjects) ${ }^{28}$ and 36 elderly (mean age 72 years; 16 vs. 20 subjects) ${ }^{30}$ untreated hypertensive patients, with candesartan in 17 (6 vs. 11 subjects) hypertensive and diabetic patients, ${ }^{26}$ and with temocapril in 36 (16 vs. 20 subjects) elderly, untreated hypertensive patients. ${ }^{30}$ In all four comparisons, nifedipine reduced brachial-ankle PWV significantly $(P \leqslant 0.02)$ less than valsartan (69 vs. $195 \mathrm{~cm} \mathrm{~s}^{-1}$ and 9 vs. $409 \mathrm{~cm} \mathrm{~s}^{-1}$ in middle-aged and elderly hypertensive patients), candesartan (189 vs. $637 \mathrm{~cm} \mathrm{~s}^{-1}$ in hypertensive and diabetic patients) and temocapril $\left(9 \mathrm{vs} .281 \mathrm{~cm} \mathrm{~s}^{-1}\right.$ in elderly hypertensive patients), despite similar or greater reductions in blood pressure by nifedipine. Cilnidipine $(n=16)$ was compared with valsartan $(n=20)$ and temocapril $(n=20)$ in untreated elderly hypertensive patients. ${ }^{30}$ Cilnidipine $\left(209 \mathrm{~cm} \mathrm{~s}^{-1}\right)$ reduced brachial-ankle PWV significantly $(P<0.01)$ less than valsartan $\left(409 \mathrm{~cm} \mathrm{~s}^{-1}\right)$, but was comparable to temocapril $\left(281 \mathrm{~cm} \mathrm{~s}^{-1}\right)$.

Three trials studied left ventricular hypertrophy using two different CCBs (amlodipine ${ }^{31,21}$ and cilnidipine ${ }^{29}$ ) in comparison with ACE inhibitors (enalapril ${ }^{31}$ or quinapril ${ }^{29}$ ) or an ARB (valsartan ${ }^{21}$ ). After 6 months of treatment with amlodipine, 43 hypertensive patients were randomly assigned to receive candesartan $(n=22)$ or to continue amlodipine $(n=21)$ for 6 months. After 6 months of the randomized treatment, the left ventricular mass index was significantly reduced by amlodipine (102 to $\left.92 \mathrm{~g} \mathrm{~m}^{-2} ; P<0.05\right)$, but not by candesartan $(103$ to $\left.98 \mathrm{~g} \mathrm{~m}^{-2}\right) .{ }^{21}$ However, in 23 previously treated hypertensive patients with left ventricular hypertrophy (left ventricular mass index $\geqslant 125 \mathrm{~g} \mathrm{~m}^{-2}$ in men and $\geqslant 120 \mathrm{~g} \mathrm{~m}^{-2}$ in women), left ventricular mass index was not influenced by amlodipine after 12 weeks of treatment $\left(n=13 ; 142\right.$ to $\left.141 \mathrm{~g} \mathrm{~m}^{-2}\right)$ but was significantly $(P<0.05)$ reduced by enalapril $\left(n=10 ; 144\right.$ to $\left.121 \mathrm{~g} \mathrm{~m}^{-2}\right) .31$ In 60 patients with mild hypertension, after 12 months of treatment, left ventricular mass index was significantly reduced by both cilnidipine $(n=30 ; 121$ to $\left.106 \mathrm{~g} \mathrm{~m}^{-2} ; P=0.003\right)$ and quinapril $\left(n=30 ; 127\right.$ to $\left.116 \mathrm{~g} \mathrm{~m}^{-2} ; P=0.02\right)$. The relative change tended to be greater for patients taking cilnidipine than for those taking quinapril $(10.6$ vs. $7.6 \% ; P=0.09){ }^{29}$

Two trials studied carotid IMT using amlodipine in comparison with ARBs (candesartan, ${ }^{24}$ losartan, ${ }^{24}$ telmisartan ${ }^{24}$ or valsartan ${ }^{19,24}$ ).
In an open, randomized study, 104 hypertensive patients with type 2 diabetes were randomly allocated to the amlodipine group $(n=58)$ or the ARB group $(n=46)$. The ARB group patients received candesartan (4-8 mg per day), losartan (25-50 mg per day), telmisartan (20-40 mg per day) or valsartan (40-80 mg per day). After an average follow-up of 56.9 weeks, amlodipine, compared with ARBs, significantly decreased carotid IMT $(-46 v s$. $+80 \mu \mathrm{m} ; P<0.05)$. IMT measurement was calculated as the mean of three measurements including one at the site of the greatest thickness and two at sites $1 \mathrm{~cm}$ proximal and $1 \mathrm{~cm}$ distal to the first site. ${ }^{24}$ However, in another study of 100 untreated hypertensive patients, after 12 months of follow-up, neither amlodipine $(n=50)$ nor valsartan $(n=50)$ significantly influenced carotid maximum IMT. $^{19}$

Two trials studied proteinuria or albuminuria using two different CCBs (efonidipine ${ }^{25}$ and amlodipine ${ }^{19}$ ) in comparison with ACE inhibitors $^{25}$ (enalapril, lisinopril or imidapril) and an ARB (valsar$\tan ) .{ }^{19}$ In hypertensive patients with renal impairment (serum creatinine, $>1.5 \mathrm{mg} \mathrm{dl}^{-1}$ ) or chronic renal parenchymal disease, after 48 weeks of treatment, efonidipine $(n=23)$ and ACE inhibitors $(n=20)$ produced similar reductions in blood pressure (efonidipine, 161/93142/82 mm Hg; ACE inhibitors, 163/95-141/83 mm Hg) and did not significantly influence urinary protein excretion $(P>0.05)$. However, in 22 patients with advanced proteinuria ( $>1 \mathrm{~g}$ per day), both efonidipine and ACE inhibitors significantly $(P<0.05)$ decreased urinary protein excretion (efonidipine, 2.7 to $2.1 \mathrm{~g}$ per day; ACE inhibitor, 3.0 to $2.0 \mathrm{~g}$ per day). ${ }^{25}$ In untreated hypertensive patients, after 12 months of follow-up, valsartan $(n=50)$, but not amlodipine, significantly $(P<0.05)$ decreased urinary albumin excretion (valsartan group 40.9 to $18.6 \mathrm{mg} \mathrm{g}^{-1}$ of creatinine), despite similar blood pressure reductions. ${ }^{19}$

Coronary lumen diameter, ${ }^{27}$ cerebral blood flow ${ }^{15}$ and microcirculation ${ }^{16}$ were each studied in one trial. Of the 1665 patients enrolled in the JMIC-B (Japan Multicenter Investigation for Cardiovascular Diseases-B) study, 183 patients participated in the quantitative coronary angiography substudy and had qualified coronary angiograms for analysis. Possible coronary vasodilatation, which may be caused by nifedipine, was excluded by the administration of sufficient isosorbide dinitrate. The minimum luminal diameter of the coronary artery in all measured segments decreased significantly from baseline in the ACE 


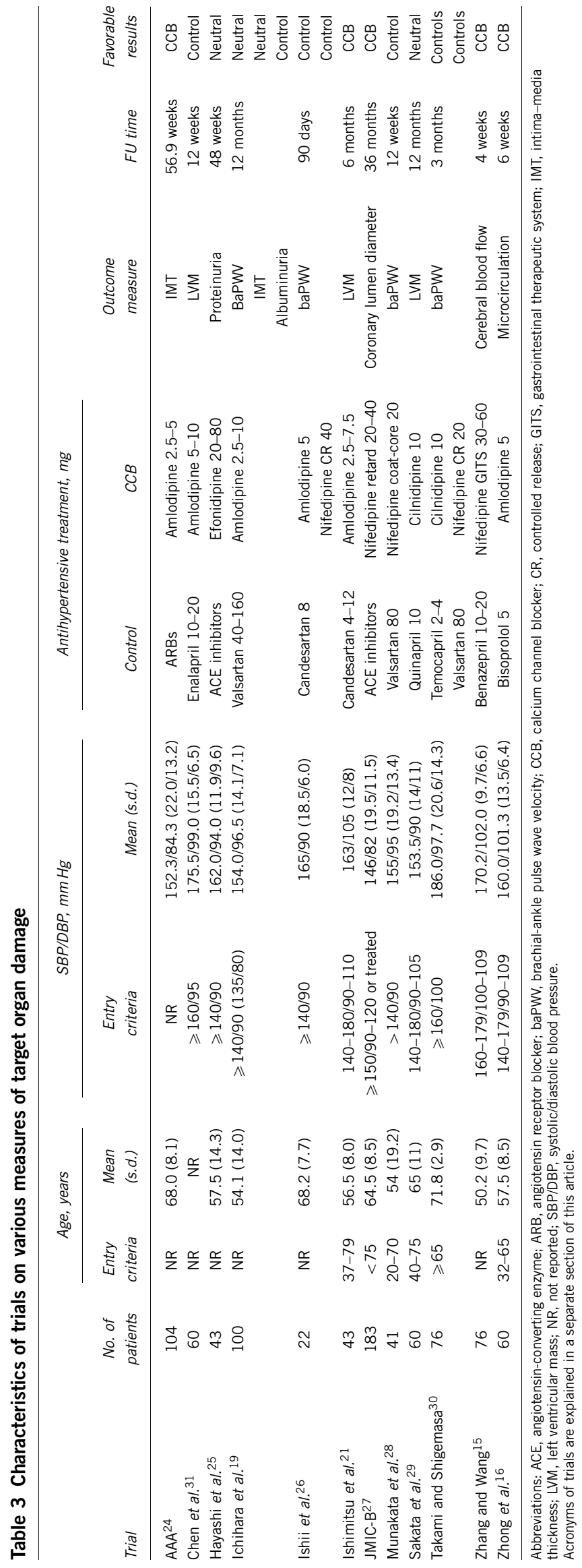

inhibitor group $(n=88 ;-0.12 \mathrm{~mm} ; P<0.001)$, but not in the nifedipine retard group $(n=95 ;-0.02 \mathrm{~mm} ; P=0.54)$, with a significant difference between the two groups $(P=0.002) .{ }^{27}$ In 76 patients with hypertension, nifedipine GITS $(n=38)$ was compared with benazepril $(n=38)$ in cerebral hemodynamics measured by transcranial Doppler of the middle cerebral arteries. After 4 weeks of treatment, nifedipine GITS, compared with benazepril, significantly increased the blood flow velocity and lowered the blood pulse index. ${ }^{15}$ In 60 patients with hypertension, amlodipine $(n=30)$ was compared with bisoprolol $(n=30)$, and the microcirculation was measured at the left ring fingernail. After 6 weeks of treatment, amlodipine significantly improved microcirculation compared with bisoprolol. ${ }^{16}$

More recently, Matsui et al..$^{32}$ compared a CCB (azelnidipine) with a diuretic (hydrochlorothiazide) as an add-on drug to olmesartan monotherapy in 207 hypertensive patients (mean age 68.4 years). After 12 weeks of treatment with olmesartan monotherapy (20 mg per day), patients were randomly assigned to receive $20 \mathrm{mg}$ azelnidipine per day $(n=103)$ or $12.5 \mathrm{mg}$ hydrochlorothiazide per day $(n=104)$ for 24 weeks. The olmesartan/azelnidipine combination, compared with the olmesartan/hydrochlorothiazide combination, significantly reduced central systolic blood pressure and the aortic PWV, with a between-group difference of $5.2 \mathrm{~mm} \mathrm{Hg}(P=0.04)$ and $0.8 \mathrm{~m} \mathrm{~s}^{-1}$ $(P<0.001)$, respectively. The two combinations had similar influences on the brachial systolic blood pressures with a between-group difference of $2.6 \mathrm{~mm} \mathrm{Hg}(P=0.29)$.

\section{PREVENTION OF CARDIOVASCULAR EVENTS}

The dihydropyridine CCBs have been intensively investigated against various classes of antihypertensive drugs in large outcome trials in Europe and North America, including the ACCOMPLISH (Avoiding Cardiovascular Events through COMbination Therapy in Patients LIving with Systolic Hypertension), ${ }^{33}$ ALLHAT (Antihypertensive and Lipid-Lowering Treatment to Prevent Heart Attack Trial), ${ }^{34,35}$ ASCOT (Anglo-Scandinavian Cardiac Outcomes Trial) ${ }^{36}$ and VALUE (Valsartan Antihypertensive Long-term Use Evaluation) ${ }^{37}$ trials with amlodipine, the STOP-2 (Swedish Trial in Old Patients with hypertension-2) trial with felodipine and isradipine ${ }^{38}$ and the INSIGHT (International Nifedipine GITS Study-Intervention as a Goal for Hypertension Therapy) trial with nifedipine GITS. ${ }^{39}$ In the amlodipine trials, ${ }^{33-37}$ amlodipine reduced systolic blood pressure slightly less than chlothalidone $(+1.0 \mathrm{~mm} \mathrm{Hg})^{34}$ and slightly more than lisinopril in ALLHAT $(-1.5 \mathrm{~mm} \mathrm{Hg}),{ }^{35}$ valsartan in VALUE $(-2.0 \mathrm{~mm} \mathrm{Hg}),{ }^{37}$ atenolol in ASCOT $(-2.8 \mathrm{~mm} \mathrm{Hg})^{36}$ and hydrochlorothiazide in ACCOMPLISH $(-0.9 \mathrm{~mm} \mathrm{Hg}){ }^{33}$ Amlodipine provided similar or increased protection against stroke and myocardial infarction in comparison with chlothalidone $(-7$ and $-2 \%),{ }^{34}$ lisinopril $(-23 \%(P=0.003)$ and $-1 \%),{ }^{35}$ valsartan $(-15 \%(P=0.08)$ and $-19 \%(P=0.02)),{ }^{37}$ atenolol $(-23 \%(P=0.0003)$ and $-13 \%$ $(P=0.05))^{36}$ and hydrochlorothiazide $(-16$ and $-22 \%(P=0.04)){ }^{33}$ In the STOP-2 trial, felodipine or isradipine was compared with the ACE inhibitor and diuretic/ $\beta$-blocker groups. Both felodipine and isradipine reduced systolic blood pressure equivalently compared with the other medications and provided slightly superior protection against stroke $(-2$ and $-12 \%(P=0.16))$, but inferior protection against myocardial infarction $(+23 \% \quad(P=0.02)$ and $+18 \%$ $(P=0.13)) .{ }^{38}$ In the INSIGHT trial, nifedipine GITS, compared with co-amilozide (hydrochlorothiazide $25 \mathrm{mg}$ /amiloride $2.5 \mathrm{mg}$ ), reduced systolic blood pressure similarly and provided slightly superior protection against stroke $(-13 \% ; P=0.60)$, but slightly inferior protection against myocardial infarction $(+20 \% ; P=0.19) .{ }^{39}$ In summary, in these trials, which were predominantly conducted with Caucasian subjects, 
CCBs provided more protection against stroke but had divergent effects on the risk of myocardial infarction, with favorable results in the amlodipine trials. ${ }^{7,8}$

In Eastern Asians, CCBs were compared with other classes of antihypertensive drugs in four trials on various disease conditions: the CASE-J (Candesartan Antihypertensive Survival Evaluation in Japan $)^{40}$ and NICS-EH (National Intervention Cooperative Study in Elderly Hypertensives $)^{41}$ trials in hypertensive patients, the JMIC-B trial in patients with hypertension and coronary heart disease ${ }^{42}$ and the JBCMI (Japanese $\beta$ blockers and Calcium Antagonists Myocardial Infarction) trial in patients within 1 month of acute myocardial infarction. ${ }^{43}$ All of these trials were conducted in Japan and had an open design (Table 4).

The CASE-J trial compared amlodipine- with candesartan-based antihypertensive regimens in 4728 high-risk hypertensive patients. To achieve the goal blood pressure of $140 / 90 \mathrm{~mm} \mathrm{Hg}$ or below, diuretics, $\alpha$ blockers, $\beta$ blockers and/or $\alpha \beta$ blockers could be added. During a mean follow-up of 3.2 years, systolic/diastolic blood pressures were 1.7/0.6 lower in the amlodipine group than in the candesartan group; however, more patients in the candesartan group required the addition of other antihypertensive drugs ( 54.5 vs. $42.7 \%$; $P<0.0001)$. With relatively small numbers, the incidences of the primary and secondary end points were not statistically different between the two groups. The risk of stroke was slightly but nonsignificantly lower in the amlodipine group than in the candesartan group ( $-23 \% ; P=0.28)$. If the results of the CASE-J trial were combined with those from the VALUE ${ }^{37}$ and IDNT ${ }^{44}$ trials that also compared amlodipine with an ARB, amlodipine would be shown to provide superior protection against stroke and myocardial infarction by 16 and $17 \%$, respectively. ${ }^{8}$

The NICS-EH (National Intervention Cooperative Study in Elderly Hypertensives) trial included only 414 hypertensive patients, compared two outdated antihypertensive drugs (sustained-release nicardipine $v s$. trichlomethiazide), had only a total of 39 events during 5 years of follow-up, and was thus inadequately powered. ${ }^{41}$

The JMIC-B (Japan Multicenter Investigation for Cardiovascular Diseases-B) trial compared nifedipine retard with ACE inhibitors (enalapril 5-10 mg, imidapril 5-10 mg or lisinopril 10-20 mg, once daily) in 1650 patients with both hypertension and coronary artery disease diagnosed with coronary angiography (stenosis $\geqslant 75 \%$ ), a history of angina pectoris ( $>2$ episodes per week) or ST-segment depression of at least $1 \mathrm{~mm}$ during the treadmill exercise test. ${ }^{42}$ During a mean follow-up of 36 months, blood pressure reductions were greater in the nifedipine group than in the ACE inhibitor group (-4/ $-1 \mathrm{~mm} \mathrm{Hg}$ ). The incidence of the primary end point (cardiac events: cardiac death or sudden death, myocardial infarction, hospitalization for angina pectoris or heart failure, serious arrhythmia and need for coronary interventions) was similar in the nifedipine (116 events, $14.0 \%$ ) and ACE inhibitor (106 events, $12.9 \%$ ) groups (+5\%; $P=0.75)^{42}$

The JBCMI trial compared dihydropyridine CCBs (amlodipine, manidipine, slow-release nifedipine and nisoldipine; $n=545$ ) with $\beta$ blockers (atenolol, bisoprolol, calvedilol and metoprolol; $n=545$ ) in 1090 patients within 1 month after acute myocardial infarction. ${ }^{43}$ At baseline, $52 \%$ of patients had a history of hypertension. During a mean follow-up of 455 days, the incidence rates of cardiovascular mortality, recurrent myocardial infarction, refractory angina and nonfatal stroke did not differ between the two groups. However, the incidence of congestive heart failure (4.2 vs. $1.1 \% ; P=0.001)$ and coronary spasm ( 1.2 vs. $0.2 \% ; P=0.03$ ) was significantly lower in the CCB group than in the $\beta$-blocker group. ${ }^{43}$

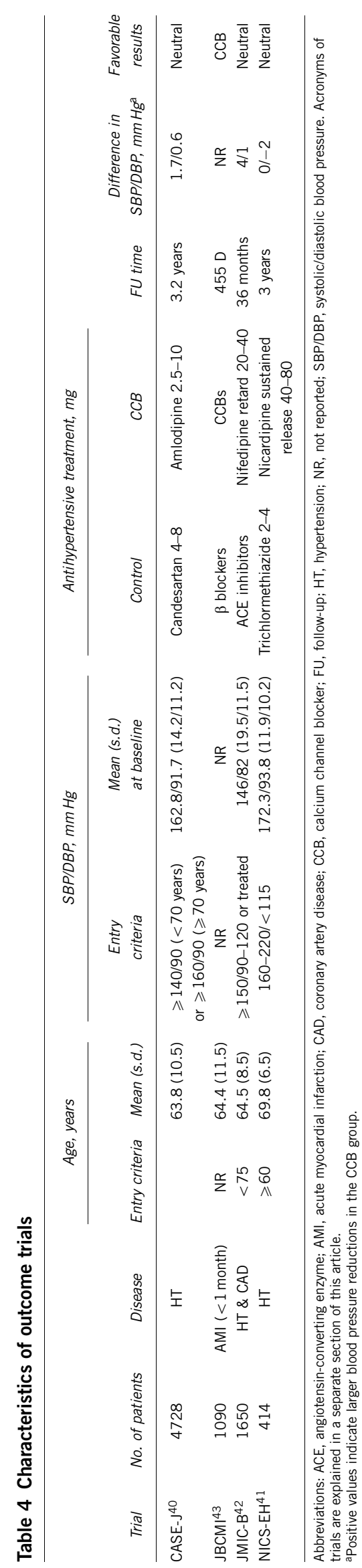




\section{PERSPECTIVES AND CONCLUSIONS}

In Eastern Asians, monotherapy with the recommended dosages of the dihydropyridine CCBs, mainly amlodipine, is more efficacious in lowering blood pressure when compared with other classes of antihypertensive drugs. The difference in the 24 -h systolic/diastolic blood pressure measurements between the groups could be as large as $5 / 3 \mathrm{~mm} \mathrm{Hg}$. This superiority, among others, can be a driving factor for the wide and even wider use of CCBs in the Asian region.

With regard to target organ protection with CCBs, the evidence in Eastern Asians is rather weak. The results of these trials were sometimes contradictory, probably because of chance findings in small studies, and might be dependent on the choice of agents or the measures of target organ damage. Moreover, it is noteworthy that the improvement in these intermediate measures of target organ damage cannot necessarily be translated into prevention of stroke and myocardial infarction, although these measures might be predictive of cardiovascular events in observational studies. Nonetheless, these studies could generate valuable hypotheses to be tested in outcome trials.

The actively controlled trials in Eastern Asians, although few and small, provided evidence on the use of CCBs in the prevention of cardiovascular events. These studies confirmed the findings of previous placebo-controlled trials in the Eastern Asian region and were consistent with the results of large outcomes trials in Europe and North America. CCBs might provide superior protection against stroke and coronary spasm. These advantages of CCBs might be particularly relevant for cardiovascular prevention in the Eastern Asian region, where stroke is the major complication of hypertension and coronary spasm is prevalent and probably one of the major causes of myocardial infarction. ${ }^{45}$ In addition, specific agents such as amlodipine might also provide similar or even superior protection against myocardial infarction.

According to the current evidence in trials on blood pressure control, target organ protection and cardiovascular prevention in Eastern Asians, CCBs should probably be recommended as the preferred drug in the management of hypertension in the Eastern Asian region to improve blood pressure control and to confront the aggravating epidemic of stroke and coronary artery disease. National guidelines in the region, and possibly regional guidelines in the future, should provide clearer recommendations on the choice of antihypertensive drugs and recommend the use of CCBs as the initial therapy in patients with uncomplicated hypertension.

\section{ACRONYMS}

AAA (Amlodipine vs. ARB in Atherosclerosis study); 24 ACCOMPLISH (Avoiding Cardiovascular Events through COMbination Therapy in Patients LIving with Systolic Hypertension); ${ }^{33}$ AngloScandinavian Cardiac Outcomes Trial); ${ }^{36}$ CASE-J (Candesartan Antihypertensive Survival Evaluation in Japan Trial); ${ }^{44}$ FEVER (Felodipine Event Reduction Study); ${ }^{4}$ JBCMI (Japanese $\beta$ blockers and Calcium Antagonists Myocardial Infarction); ${ }^{43}$ JMIC-B (Japan Multicenter Investigation for Cardiovascular Diseases-B); ${ }^{42}$ ALLHAT (Antihypertensive and Lipid-Lowering Treatment to Prevent Heart Attack Trial); ${ }^{34,35}$ INSIGHT (International Nifedipine GITS Study-Intervention as a Goal for Hypertension Therapy); ${ }^{39}$ NICS-EH (National Intervention Cooperative Study in Elderly Hypertensives); ${ }^{41}$ STOP2 (Swedish Trial in Old Patients with hypertension-2); ${ }^{38}$ Syst-China (Systolic Hypertension in China trial); ${ }^{1,2}$ VALUE (Valsartan Antihypertensive Long-term Use Evaluation). ${ }^{37}$

\section{ACKNOWLEDGEMENTS}

The review writing committee, organized by the Asian Pacific Heart Association and with support from Pfizer, China, convened several times to communicate and discuss the management of hypertension in general and the use of calcium channel blockers in Eastern Asians in particular. The sponsor of the meetings had no role in the concept and design, in the collection and analysis of data, or in the drafting and revision of this review. Dr Wang reports receiving funding from the National Natural Science Foundation of China (Grants 30871360 and 30871081) and the Ministry of Science and Technology (Grant 2006BAI01A03), Beijing, China; the Shanghai Commissions of Science and Technology (Grant 07JC14047 and the 'Rising Star' program 06QA14043) and Education (Grant 07ZZ32 and the 'Dawn' project 08SG20); the Shanghai Shenkang Hospital Development Centre (Grant SHDC12007318); and the European Union (Grants IC15-CT98-0329-EPOGH, LSHM-CT-2006-037093 and HEALTH-F4-2007-201550). He also receives consulting and lecture fees from AstraZeneca, Bayer, GSK, Merck, Novartis, Pfizer, Sankyo and Servier. We gratefully acknowledge the assistance of Dr Qi-Fang Huang (The Shanghai Institute of Hypertension, Shanghai, China).

1 Liu L, Wang JG, Gong L, Liu G, Staessen JA. Comparison of active treatment and placebo for older Chinese patients with isolated systolic hypertension. J Hypertens 1998; 16: 1823-1829.

2 Wang JG, Staessen JA, Gong L, Liu L. Chinese trial on isolated systolic hypertension in the elderly. Arch Intern Med 2000; 160: 211-220.

3 Gong L, Zhang W, Zhu Y, Zhu J, Kong D, Pagé V, Ghadirian P, LeLorier J, Hamet P. Shanghai trial of nifedipine in the elderly (STONE). J Hypertens 1996; 14: 1237-1245.

4 Liu L, Zhang Y, Liu G, Li W, Zhang X, Zanchetti A. The Felodipine Event Reduction (FEVER) Study: a randomized long-term placebo-controlled trial in Chinese hypertensive patients. J Hypertens 2005; 23: 2157-2172.

5 Zhou BF, Stamler J, Dennis B, Moag-Stahlberg A, Okuda N, Robertson C, Zhao L, Chan $Q$, Elliott P. Nutrient intakes of middle-aged men and women in China, Japan, United Kingdom, and United States in the late 1990s: the INTERMAP study. J Hum Hypertens 2003; 17: 623-630.

6 Dwivedi G, Beevers DG. Hypertension in ethnic groups: epidemiological and clinical perspectives. Expert Rev Cardiovasc Ther 2009; 7: 955-963.

7 Staessen JA, Wang JG, Thijs L. Cardiovascular prevention and blood pressure reduction: a meta-analysis. Lancet 2001; 358: 1305-1315.

8 Wang JG, Li Y, Franklin S, Safar M. Prevention of stroke and myocardial infarction by amlodipine and angiotensin receptor blockers: a quantitative overview. Hypertension 2007; 50: 181-188.

9 Pristipino C, Beltrame JF, Finocchiaro ML, Hattori R, Fujita M, Mongiardo R, Cianflone D, Sanna T, Sasayama S, Maseri A. Major racial differences in coronary constrictor response between Japanese and Caucasians with recent myocardial infarction. Circulation 2000; 101: 1102-1108.

10 Sueda S, Kohno H, Fukuda H, Uraoka T. Did the widespread use of long-acting calcium antagonists decrease the occurrence of variant angina? Chest 2003; 124: 2074-2078.

11 Cao ZF, Duan H, Song LR. Comparison of amlodipine, fosinopril and indapamide in blood pressure lowering efficacy. Chin Hosp Pharm J 2001; 21: 297-298 (in Chinese).

$12 \mathrm{Li} \mathrm{L}$, Song Y, Cai W. Effects of amlodipine and peridopril on $24 \mathrm{~h}$ ambulatory blood pressure in hypertensive patients. Chin J Factory Mineral Med 2002; 15: 111-112 (in Chinese).

13 Tomlinson B, Woo J, Thomas GN, Chau YM, Critchley JA. Randomized, controlled, parallel-group comparison of ambulatory and clinic blood pressure responses to amlodipine or enalapril during and after treatment in adult Chinese patients with hypertension. Clin Ther 2004; 26: 1292-1304.

14 Zhang DL, Li NF, Wang XL, Zhou KM. Comparison of the effects of amlodipine and enalapril in $24 \mathrm{~h}$ ambulatory blood pressure in elderly patients with isolated systolic hypertension. Chin J Atheroscler 2005; 13: 58-60 (in Chinese).

15 Zhang X. Wang S. The effect of nifedipine GITS tablet on ambulatory blood pressure and cerebral hemodynamics in patients with essential hypertension. Clin Med J Chin 2001; 8: 473-475 (in Chinese).

16 Zhong ZH, Liu GS, Meng FH, Li HX, Liu FY, Li XH, Zhao XM. Efficacy and T/P ratio of amlodipine and bisoprolol in essential hypertension monotherapy and effect on microcirculation. Chin J New Drugs Clin Remedy 2001; 20: 293-296 (in Chinese).

17 Eguchi K, Kario K, Shimada K. Differential effects of a long-acting angiotensin converting enzyme inhibitor (temocapril) and a long-acting calcium antagonist (amlodipine) on ventricular ectopic beats in older hypertensive patients. Hypertens Res 2002; 25: 329-333.

18 Eguchi K, Kario K, Hoshide Y, Hoshide S, Ishikawa J, Morinari M, Ishikawa S, Shimada K. Comparison of valsartan and amlodipine on ambulatory and morning blood pressure in hypertensive patients. Am J Hypertens 2004; 17: 112-117.

19 Ichihara A, Kaneshiro Y, Takemitsu T, Sakoda M. Effects of amlodipine and valsartan on vascular damage and ambulatory blood pressure in untreated hypertensive patients. J Hum Hypertens 2006; 20: 787-794.

20 Ishimitsu T, Minami J, Yoshii M, Suzuki T, Inada H, Ohta S, Futoh Y, Ono H, Matsuoka H. Comparison of the effects of amlodipine and losartan on 24-h ambulatory blood pressure in hypertensive patients. Clin Exp Hypertens 2002; 24: 41-50. 
21 Ishimitsu T, Kobayashi T, Honda T, Takahashi M, Minami J, Ohta S, Inada H, Yoshii M, $\mathrm{Ono} \mathrm{H}$, Matsuoka $\mathrm{H}$. Protective effects of an angiotensin II receptor blocker and a longacting calcium channel blocker against cardiovascular organ injuries in hypertensive patients. Hypertens Res 2005; 28: 351-359.

22 Chinese Hypertension Guidelines Committee. Chinese guidelines on the management of hypertension. Chin J Hypertens 2005; 13(Suppl): 2-41 (in Chinese).

23 Ogihara T, Kikuchi K, Matsuoka H, Fujita T, Higaki J, Horiuchi M, Imai Y, Imaizumi T, Ito S, Iwao H, Kario K, Kawano Y, Kim-Mitsuyama S, Kimura G, Matsubara H, Matsuura H, Naruse M, Saito I, Shimada K, Shimamoto K, Suzuki H, Takishita S, Tanahashi N, Tsuchihashi T, Uchiyama M, Ueda S, Ueshima H, Umemura S, Ishimitsu T, Rakugi H. The Japanese society of hypertension guidelines for the management of hypertension (JSH 2009). Hypertens Res 2009; 32: 3-107.

24 Ikeda H, Minamikawa J, Nakamura Y, Honjo S, Hamamoto Y, Wada Y, Nabe K, Koshiyama $\mathrm{H}$. Comparison of effects of amlodipine and angiotensin receptor blockers on the intima-media thickness of carotid arterial wall (AAA study: amlodipine vs. ARB in atherosclerosis study). Diabetes Res Clin Pract 2009; 83: 50-53.

25 Hayashi K, Kumagai H. Saruta T. Effect of efonidipine and ACE inhibitors on proteinuria in human hypertension with renal impairment. Am J Hypertens 2003; 16: 116-122.

26 Ishii H. Tsukada T, Yoshida M. Angiotensin II type-I receptor blocker, candesartan, improves brachial-ankle pulse wave velocity independent of its blood pressure lowering effects in type 2 diabetes patients. Intern Med 2008; 47: 2013-2018.

27 Shinoda E, Yui Y, Kodama K, Hirayama A, Nonogi H, Haze K, Sumiyoshi T, Hosoda S, Kawai C. Quantitative coronary angiogram analysis: nifedipine retard versus angiotensin-converting enzyme inhibitors (JMIC-B side arm study). Hypertension 2005; 45: $1153-1158$

28 Munakata M, Nagasaki A, Nunokawa T, Sakuma T, Kato H, Yoshinaga K, Toyota T. Effects of valsartan and nifedipine coat-core on systemic arterial stiffness in hypertensive patients. Am J Hypertens 2004; 17: 1050-1055.

29 Sakata K, Yoshida H, Tamekiyo H, Obayashi K, Nawada R, Doi O, Mori N. Comparative effect of clinidipine and quinapril on left ventricular mass in mild essential hypertension. Drugs Exp Clin Res 2003; 29: 117-123.

30 Takami T, Shigemasa M. Efficacy of various antihypertensive agents as evaluated by indices of vascular stiffness in elderly hypertensive patients. Hypertens Res 2003; 26: 609-614.

31 Chen W, Xu Q, Ji Y. Comparison of amlodipine and enalapril in treatment of hypertension. Chin J Hypertens 1997; 5(Suppl): 59-61 (in Chinese).

32 Matsui Y, Eguchi K, O'Rourke MF, Ishikawa J, Miyashita H, Shimada K, Kario K. Differential effects between a calcium channel blocker and a diuretic when used in combination with angiotensin II receptor blocker on central aortic pressure in hypertensive patients. Hypertension 2009; 54: 716-723.

33 Jamerson K, Weber MA, Bakris GL, Dahlöf B, Pitt B, Shi V, Hester A, Gupte J, Gatlin M, Velazquez EJ. Benazepril plus amlodipine or hydrochlorothiazide for hypertension in high-risk patients. N Engl J Med 2008; 359: 2417-2428.

34 ALLHAT Officers, Coordinators for the ALLHAT Collaborative Research Group. The Antihypertensive and Lipid-Lowering Treatment to Prevent Heart Attack Trial. Major outcomes in high-risk hypertensive patients randomized to angiotensin-converting enzyme inhibitor or calcium channel blocker vs diuretic: the Antihypertensive and
Lipid-Lowering Treatment to Prevent Heart Attack Trial (ALLHAT). JAMA 2002; 288: 2981-2997.

35 Leenen FH, Nwachuku CE, Black HR, Cushman WC, Davis BR, Simpson LM, Alderman MH, Atlas SA, Basile JN, Cuyjet AB, Dart R, Felicetta JV, Grimm RH, Haywood LJ, Jafri SZ, Proschan MA, Thadani U, Whelton PK, Wright JT. Clinical events in high-risk hypertensive patients randomly assigned to calcium channel blocker versus angiotensin-converting enzyme inhibitor in the antihypertensive and lipid-lowering treatment to prevent heart attack trial. Hypertension 2006; 48: 374-384.

36 Dahlöf B, Sever PS, Poulter NR, Wedel H, Beevers DG, Caulfield M, Collins R, Kjeldsen SE, Kristinsson A, McInnes GT, Mehlsen J, Nieminen M, O'Brien E, Ostergren J. Prevention of cardiovascular events with an amlodipine_perindopril strategy compared with an atenolol_thiazide strategy. The Anglo-Scandinavian Cardiac Outcomes TrialBlood Pressure Lowering Arm (ASCOT-BPLA): a multicentre randomised controlled trial. Lancet 2005; 366: 895-906.

37 Julius S, Kjeldsen SE, Weber M, Brunner HR, Ekman S, Hansson L, Hua T, Laragh J, McInnes GT, Mitchell L, Plat F, Schork A, Smith B, Zanchetti A. Outcomes in hypertensive patients at high cardiovascular risk treated with valsartan- or amlodipine-based regimens: VALUE, a randomised trial. Lancet 2004; 63: 2022-2031.

38 Hansson L, Lindholm LH, Ekbom T, Dahlöf B, Lanke J, Scherstén B, Wester PO, Hedner $\mathrm{T}$, de Faire $\mathrm{U}$. Randomised trial of old and new antihypertensive drugs in elderly patients: cardiovascular mortality and morbidity the Swedish Trial in Old Patients with Hypertension-2 study. Lancet 1999; 354: 1751-1756.

39 Brown MJ, Palmer CR, Castaigne A, de Leeuw PW, Mancia G, Rosenthal T, Ruilope LM. Morbidity and mortality in patients randomised to double-blind treatment with a longacting calcium-channel blocker or diuretic in the International Nifedipine GITS study: Intervention as a Goal in Hypertension Treatment (INSIGHT). Lancet 2000; 356: 366-372.

40 Ogihara T, Nakao K, Fukui T, Fukiyama K, Ueshima K, Oba K, Sato T, Saruta T. Effects of candesartan compared with amlodipine in hypertensive patients with high cardiovascular risks: candesartan antihypertensive survival evaluation in Japan trial. Hypertension 2008; 51: 393-398.

41 National Intervention Cooperative Study in Elderly Hypertensives Study Group. Randomized double-blind comparison of a calcium antagonist and a diuretic in elderly hypertensives. Hypertension 1999; 34: 1129-1133.

42 Yui Y, Sumiyoshi T, Kodama K, Hirayama A, Nonogi H, Kanmatsuse K, Origasa H, limura O, Ishii M, Saruta T, Arakawa K, Hosoda S, Kawai C. Comparison of nifedipine retard with angiotensin converting enzyme inhibitors in Japanese hypertensive patients with coronary artery disease: the Japan Multicenter Investigation for Cardiovascular Diseases-B (JMIC-B) randomized trial. Hypertens Res 2004; 27: 181-191.

43 Japanese Beta-Blockers, Calcium Antagonists Myocardial Infarction (JBCMI) Investigators. Comparison of the effects of beta blockers and calcium antagonists on cardiovascular events after acute myocardial infarction in Japanese subjects. Am J Cardiol 2004; 93: 969-973.

44 Lewis EJ, Hunsicker LG, Clarke WR, Berl T, Pohl MA, Lewis JB, Ritz E, Atkins RC, Rohde R, Raz I. Renoprotective effect of the angiotensin-receptor antagonist irbesartan in patients with nephropathy due to type 2 diabetes. N Engl J Med 2001; 345: 851-860.

45 Sasayama S. Heart disease in Asia. Circulation 2008; 118: 2669-2671. 